\title{
Interactions of Fish Sector and Non-Fish Sector in DSGE Model
}

\author{
Wei $\mathrm{Li}^{1}$ \\ ${ }^{1}$ Graduate School of Chinese Academy of Social Sciences, China \\ Correspondence: Wei Li, Graduate School of Chinese Academy of Social Sciences, China. E-mail: \\ aliwei0911@yahoo.com.cn
}

Received: February 10, 2013 Accepted: March 5, 2013 Online Published: April 15, 2013

doi:10.5539/jas.v5n5p244 URL: http://dx.doi.org/10.5539/jas.v5n5p244

\begin{abstract}
This paper presents a three sector models showing that the shock of preference of non-fish has only effect on non-fish production, and fish production increase of labor can both influence fish and non-fish sector. But the influence is higher in the non-fish sector. Labor shock can increase the investment and labor in the fish sector and decrease investment and labor in the non-fish sector. This may be caused by high labor share and changes in work in the fish sector.
\end{abstract}

Keywords: shocks, fish sector, non-fish sector

\section{Introduction}

Two definitive characteristics of China economy, as a whole, after performing the reform and opening-up policy in 1978, are the fast and stable growth in GDP and strong investment. As a part of total investment, fish investment also has experienced fast increase, even with a sharper increase. But statistic data shows that total catch displays the other direction before 1999, forcing an upward trend thereafter, a slight move downward follow end by a rapid decrease. To understand these economic phenomena, it is crucial to answer two questions: (1) what is the key factor(s), causing the violent fluctuation of fish catch? (2) While the whole economy is stable, what are effects of the fish industry on the whole economy?

In this paper, we address these problems with a quantitative model. We develop and estimate using a Bayesian likelihood approach, a dynamic stochastic general equilibrium model of the China economy that models the price and the production of the fish market. We do so with two goals in mind. Firstly, we need to understand changes in preference in fish and non-fish production, and labor, respectively. Secondly, to estimate the spillovers from the fish industry to the wider economy, the model should reproduce some key features of the data.

Our analysis combines two elements: (1) a multi-sector structure with fish and non-fish goods; (2) a rich set of shocks, which are essential for the model specification

In most articles, only one sector is often discussed; the fish industry, to the best of my knowledge is often ignored. However, there are many papers that consider the uncertain factors. Uncertainty can at least be classed into four kind, process uncertainty, observation uncertainty, model uncertainty and environmental uncertainty. Clark (2010), Anderson and Seijo (2010), and Conrad (2010) have dealt with uncertainty in detail in their studies. Since in our paper we merge three sectors, some additional stochastic factors are therefore allowed; preference uncertainty, labor uncertainty, etc.

Section 2 lays out the model. Section 3 calibrates parameter estimates, where we use the model to discuss related issues to the role of fish industry in the wider economy. Section 4 , concludes.

\section{The Model}

The model features sector heterogeneity. On the demand side, households maximize the utility. They can freely allocated work hours between fish industry and non-fish industry (denoted as a common industry). They consume fish and non-fish items with taken prices; they own capital of the economy and supply funds to either fish firm or non-fish firms.

On the supply side, there are two sectors. To maximize the profit, fish firms hire workers, use fund and sell the produce. The common firms have no difference except that they have no constrains from nature, because production of fish firms is strongly influenced by fish's natural growth process. 


\subsection{Households}

There is a continuum of measure 1 of agents. It is a representative household that maximizes the expected present value of lifetime utility as given by:

$$
\begin{gathered}
E_{t=0}^{\infty} \beta^{t}\left(z_{t} \log \left(c_{t}-\varepsilon^{0} c_{t-1}\right)+j_{t} \log \left(f_{t}-\varepsilon^{1} f_{t-1}\right)+\tau_{t} /(1+\eta)\left(n_{c t}^{1+\xi}+n_{f t}^{1+\xi}\right)^{++\frac{1+\xi}{\xi}}\right) \\
\text { s.t. } p_{c t} c_{t}+p_{f t} f_{t}+k_{c t}+k_{f t} \\
=(1-\delta+r)\left(k_{c t-1}+k_{f t-1}\right)+w_{c t} n_{c t}+w_{f t} n_{f t} \\
\ln z_{t}=\rho_{z} \ln z_{t-1}+u_{z t}, u_{z t} \sim N\left(0, \sigma_{z}\right) \\
\ln j_{t}=\rho_{j} \ln j_{t-1}+u_{j t}, u_{j t} \sim N\left(0, \sigma_{j}\right) \\
\ln \tau_{t}=\rho_{\tau} \ln \tau_{t-1}+u_{t}, u_{\pi t} \sim N\left(0, \sigma_{\tau}\right)
\end{gathered}
$$

Variables $c, f, n_{c}$ and $n_{f}$ represent non-fish consumption, fish consumption, hours working in non-fish firms and hours working in fish firms. The discount factor is $\beta$. And symbol $E_{t}$ denotes the expectation operator based on information of time t. Random variables $z_{t} j_{t}$ and $\tau_{t}$ capture shocks to inter-temporal preference, to the demand for fish and to the supply of labor respectively. These shocks follow stationary autoregressive processes of order one:

The parameter $\varepsilon$ measures the degree of habit formation in consumption. If $\varepsilon^{0}$ and $\varepsilon^{1}$ equal zero, hours worked across the two sectors are perfect substitutes, both sectors pay the same wage in equilibrium. Positive values of $\varepsilon^{0}$ and $\varepsilon^{1}$ allow capturing some degree of sector specificity. The value of $\eta_{\text {measures }}$ the inverse elasticity of the labor supply.

Households maximize their lifetime utility subject to the budget constraint. Agents select consumption plan $c_{t}$

and $f_{t}$, capital in non-fish sector $k_{c t}$, capital in fish sector $k_{f t}$, working hours $n_{c t}$ and $n_{f t}$ to maximize their utility subject to the constraint above. We assume that No free capital market exists. Households cannot borrow money from other parts.

\subsection{Non-Fish Firms}

Non-fish firms produce non-fish item and also employ labor and capital. Firms pay wages to households and repay the returns to capital owners and the households.

The firm's problem is to maximize the profit as follows:

$$
\begin{aligned}
& \operatorname{Max}\left\{p_{c t} y_{t}-w_{c t} n_{c t}-r_{c} k_{c t-1}\right\} \\
& \text { s.t. } y_{t}=\left(a_{c t} n_{c t}\right)^{1-n} k_{c t-1}{ }^{n}
\end{aligned}
$$

The production function $y_{t}$ is Cobb-Douglas types. The price of non-fish items is $p_{c t}$. The value of $a_{c t}$ represents the technology progress.

2.3 Fish Firms

Fish firms are deeply influenced by man-made factors, labor, capital, technology, and also by natural factors such as climate, temperature, etc.

The firms' problem is to maximize the profit as follows: 


$$
\begin{aligned}
& \operatorname{Max}\left\{p_{f t} h_{t}-w_{f t} n_{f t}-r_{f} k_{f t}\right\} \\
& \text { s.t. } h_{t}=\left(a_{f t} n_{f t}\right)^{\alpha} k_{f t}^{\beta} x_{t}^{1-\alpha-\beta} \\
& \quad x_{t+1}-x_{t}=g_{t} x_{t}\left(1-x_{t} / k_{t}\right)-h_{t}
\end{aligned}
$$

Fish firms make use of the Cobb-Douglas production function, where the value of $a_{f t}$ represents the technology

progress and the value of $x_{t}$ is stock. The fish nature growth function forms the logistic model where the fish

price is $p_{f t}$.

\section{Quantitative Analysis}

\subsection{Calibration}

The model is calibrated by the year frequency data in order to match properties of the China's fish sector and other sectors. The discount factor is 0.9 , so that the average annual rate of return is $20 \%$. This is not uncommon in China, based on the following two reasons. One reason is the fast growth speed of China. The other reason is that except the government controll firms, the private firms seldom can obtain credits from the formal finance institution. So the high return rate is established by the illegal finance trades. The share of labor income in common firm is set at 0.25 , and the fish firm 0.35 which can be explained that Chinese products are so cheap and there is cheap labor. The depreciation rate is also very high at $10 \%$ and can be justified by the infrastructure fixed fee. The lack of job mobility results from the Hukou system which specifies that anyone who is not of local birth has no rights to work in the special local firms, especially in the public firms. And workers who want to change jobs from one sector to another find it difficult. According to a Chinese idiom, 'A carrot occupies a pit until it dies'.

The model is computed using Bayes theorem. We first transform the data into suitable computation. Then we chose the appropriate prior distributions for the parameters and estimate posterior distribution with Monte Carlo methods.

Table 1. Prior and posterior distribution of the structural parameters

\begin{tabular}{cccccccc}
\hline \multirow{2}{*}{ parameter } & \multicolumn{4}{c}{ Prior distribution } & \multicolumn{3}{c}{ Posterior distribution } \\
\cline { 2 - 7 } & distr & mean & st.dev & mean & 2.5 percent & median & 97.5 percent \\
\hline$\varepsilon^{0}$ & Gamma & 0.5 & 0.075 & 0.6535 & 0.6096 & 0.6548 & 0.6986 \\
$\varepsilon^{1}$ & Gamma & 0.5 & 0.075 & 0.524 & 0.494 & 0.5236 & 0.6494 \\
$\eta$ & Gamma & 0.8 & 0.1 & 0.8739 & 0.7137 & 0.816 & 0.9177 \\
$\xi$ & Normal & 1 & 0.1 & 0.5259 & 0.3141 & 0.5226 & 0.7325 \\
\hline
\end{tabular}

Table 2. Prior and posterior distribution of the shock process

\begin{tabular}{cccccccc}
\hline \multirow{2}{*}{ parameter } & \multicolumn{3}{c}{ Prior distribution } & \multicolumn{3}{c}{ Posterior distribution } \\
\cline { 2 - 7 } & distr & mean & st.dev & mean & 2.5 percent & median & 97.5 percent \\
\hline$\rho_{z}$ & Normal & 0.8 & 0.1 & 1.059 & 0.8694 & 1.0623 & 1.2640 \\
$\rho_{j}$ & Normal & 0.8 & 0.2 & 1.759 & 1.6011 & 1.762 & 1.912 \\
$\rho_{\tau}$ & Normal & 0.8 & 0.1 & 0.972 & 0.941 & 0.9726 & 1.0054 \\
$\sigma_{z}$ & Gamma & 0.01 & 0.002 & 0.64 & 0.569 & 0.641 & 0.7171 \\
$\sigma_{j}$ & Gamma & 0.01 & 0.002 & 0.847 & 0.765 & 0.847 & 0.931 \\
$\sigma_{\tau}$ & Gamma & 0.01 & 0.002 & 0.0007 & -0.0167 & 0.0072 & 0.0298 \\
\hline
\end{tabular}



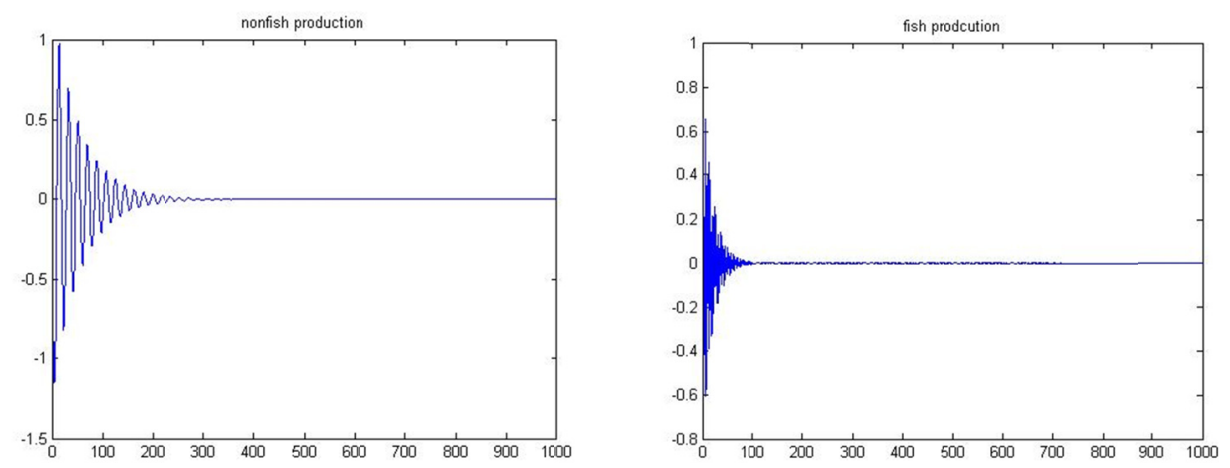

Figure 1. Impulses from common consumption preference
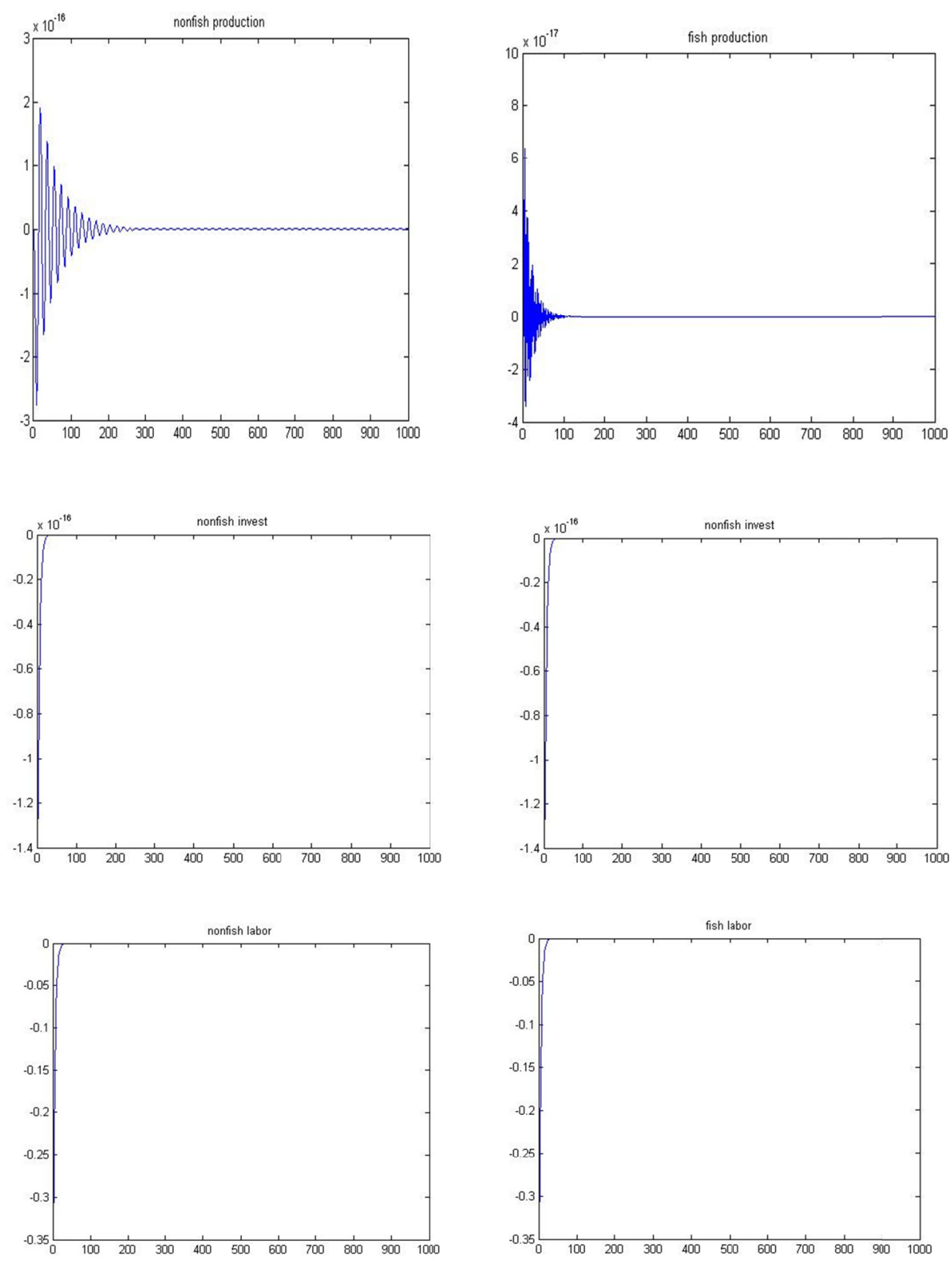

Figure 2. Impulses from fish consumption preference 


\subsection{Impulse Response}

The exogenous shocks analyzed in the simulation experiment are shock of common item preference, shock of fish item preference and shock of supply of labor. Followed by a standard deviation of common item preference as shown in Figure 1, the only change is the common item production which shows the period changes and the vibration range which becomes smaller. As household's utility function has a positive relationship with consumption. So a rational consumer should reduce the current consumption sharply to increase the next consumption extremely. Although shock does not have influence on the investment and labor supply, investment is influenced by the return rate and labor-supply by the disutility of labor and wage. And both have no relationship with item preference in our model. The fish preference shock is similar to the shock of preference of common item. There are extreme differences in the labor supply, as shown in Figure 2. With increase in labor supply, the production of fish and non-fish all get to grow although the growth of fish production is relatively small. The answer may be due to the small share labor in fish sector. But labor and investment will increase in the fish sector but decrease in the non-fish sector. This can be explained by the fact that in the fish sector labor can have a high share of 0.35 and 0.25 in the non-fish sector.

\section{Conclusion}

This paper develops a three sector DSGE model, and shows that the fish sector's growth contributes to the fish preference and non-fish preference and cannot have effects on the fish industry. However, the non-fish preference has a significant influence in the non-fish sector, with much more change range. As the labor supply grows, the production of the two sectors also shows the periodical vibration, but the range of non-fish sector is consistently fiercer. Without doubt, labor in fish sector should be increased for higher labor share. But the increase in the investment of fish sector is a surprising outcome. It may be as a result of the byproduct of the changed working force.

\section{References}

Anderon, L. G., \& Seijo. J. C. (2010). Bioeconomics of Fisheries Management. Iowa: Wiley-BlackWeil.

Clark, C. W. (2010). Mathematical Bioeconomics: the Mathematical of Conservation. Hoboken: Wiley.

Jeasen, R. (2007). The Digital Provide: Information, Market Performance, and Welfare in the South Indian Fisheries Sector. The Quarterly Journal of Economics, CXXII(3), 879-924.

Raiffa, H., \& Schilaiffer, R. (2000). Applied Statistical Decision Theory. New York: Wiley. 